\title{
Experimental Investigation of a Ground Coupled Heat Exchanger in Khulna, Bangladesh
}

\author{
Mohammad Mahmudur Rahman, Md. Fahad Hossain
}

\begin{abstract}
An attempt has been made in this work to investigate the feasibility and thermal performance of a ground coupled heat exchanger (GCHE) in the Khulna University of Engineering and Technology (KUET) campus Khulna, Bangladesh (22.900222N, 89.501847E). The GCHE system has been designed and connected to a test room adjacent to the setup to measure the cooling and heating performance during both summer and winter respectively. The heating and cooling load of the test room were $4.42 \mathrm{~kW}$ and $2.5 \mathrm{~kW}$ respectively. The experimental results were obtained from September 2008 to March 2009 during summer and winter. It was found that, in winter the system warms up the ambient (cold) air by as much as $10^{\circ}$ Cat night. In summer cools the ambient (hot) air also by as much as $12^{\circ} \mathrm{C}$ during the day. The average performance of the system (CoE)sys for the horizontal closed loop ground coupled heat exchanger was found as 6.75. It was concluded that the proposed design can be used for the heating and cooling purpose efficiently.
\end{abstract}

Index Terms-CGHE, KUET, Ground, Heat.

\section{INTRODUCTION}

Due to global climate change, sustainable energy harvesting has been a crucial matter for the entire humanity. The heating and cooling load comprises a major portion in the total energy consumption. It has been incumbent to provide a source of clean energy to such demanding energy sector. The use of ground-couple heat exchanger for space air conditioning can be a great solution. A ground-coupled heat exchanger (GCHE) is a device that absorb heat from ground and delivers to house or building during winter and reverses the process during summer. The idea is that as the air travels through the pipes, it gives up some of its heat to the surrounding soil, entering the house as cooler air. This will occur only if the earth is at least several degrees cooler than the incoming air. During cold season when air is slowly drawn using a small fan through plastic pipes buried at this depth, it will be heated providing natural climate control with much less energy than conventional heating and cooling. The ground serves as a heat sink in the summer and as a heat source in the winter, thus giving almost year-round temperature modification.

There have been various studies in the design and experimental evaluation in different corner of the globe. Thermal performance, economic analysis of the GCHE system relevant to specific need and location has been presented in abundance in the literature. In this work, performance evaluation of a horizontal GCHE with air as

Mohammad Mahmudur Rahman, Department of Industrial Engineering and Management, Khulna University of Engineering and Technology, Khulna, Bangladesh

Md Fahad Hossain, Department of Mechanical Engineering, Khulna University of Engineering and Technology, Khulna, Bangladesh working fluid has been performed in the KUET campus, Khulna Bangladesh for the first time. The initial temperature data acquired during summer and winter at various depth to determine the feasibility of the experimental design. These data have been used to design the system. Experiments conducted during summer and winter to calculate the heating and cooling performance of the system.

\section{DESIGN OF THE SYSTEM}

There are basically three configurations, an open 'fresh air' system, a closed loop design, or a combination. An attempt has been made for designing an open loop system in which following design parameter were considered

\section{A. Tube diameter}

Optimum tube diameter varies widely with tube length, tube costs, flow velocity, and flow volumes. Diameters between 15.2 and 45.7 centimeters appear to be most appropriate.

\section{B. Tube Location}

Earth temperatures and, consequently, cooling tube performance vary significantly from sunny to shady locations. Where possible, the inlets in open loop systems and the cooling tubes themselves should be placed in shady areas.

\section{Tube Depth}

Tubes should be buried at least 1.8 meters below ground level. Only rarely is burying them more than 3.7 meters justifiable. When digging trenches at these depths, cave-ins are an extreme hazard, and appropriate precautions should be taken.

\section{Earth Temperature}

The temperature of the earth at depths of 6.1-30.5 meters remain about two to three degrees higher than the mean annual air temperature. At depths less than 3.1-3.7 meters, earth temperatures may be strongly influenced by air temperatures and may vary during the year, depending on the location. Near the surface, earth temperatures closely correspond to air temperatures.

\section{E. Tube Length}

There is no simple formula for determining the proper tube length in relation to the amount of cooling desired. Local soil conditions, soil moisture, tube depth, and other site-specific factors should be considered to determine the proper length.

\section{F. Soil Properties}

The amount of heat conducted and how widely it is diffused varies from one soil type to another. The moisture content of the soil is a major influence on conductivity and diffusivity, and accounts for large variations on how heat moves through the earth. 


\section{EXPERIMENTAL SETUP FOR INITIAL DATA ACQUISITION}

For placing the thermocouples to measure temperature of different ground levels a suitable site is selected at north side of Mechanical Engineering Building, Khulna University of Engineering and Technology (KUET) campus. Deep hole with about $15 \mathrm{~cm}$ diameter and about $3.3 \mathrm{~m}$ depth was prepared to place the pipe with thermocouples at different level.

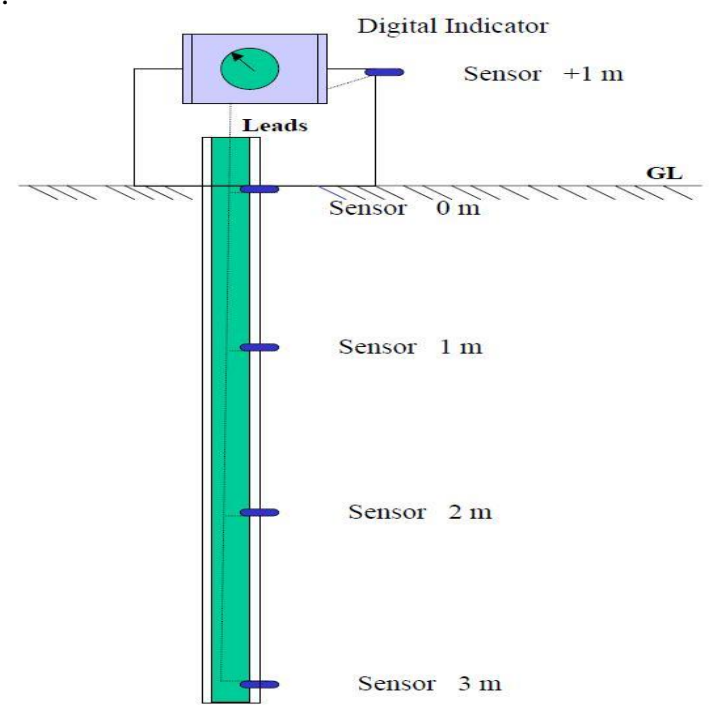

Figure 1: Thermocouple placement into the tube at different ground level

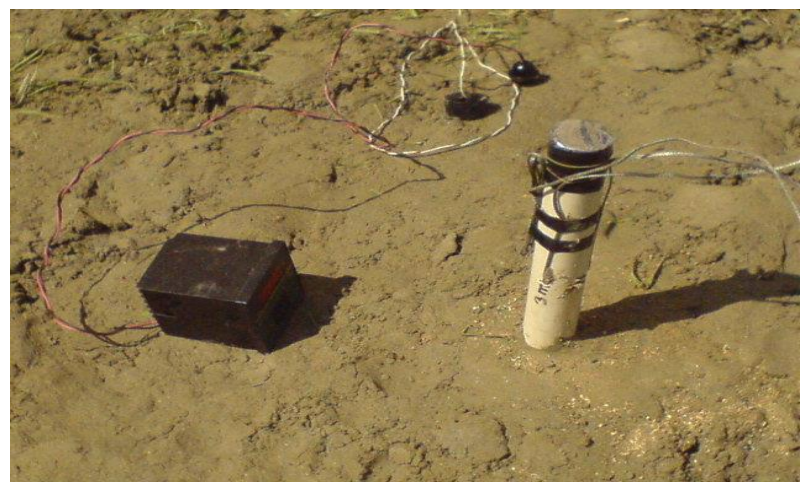

Figure 2: Temperature measuring setup

Temperatures at different ground level at different days were recorded. Then these data were analyzed to determine the exact ground position for the placement of Ground Coupled Heat Exchanger (GCHE). To observe the seasonal effect data for both summer and winter season were collected. For winter season the data of 23rd December 2008 has been shown on the figure 3

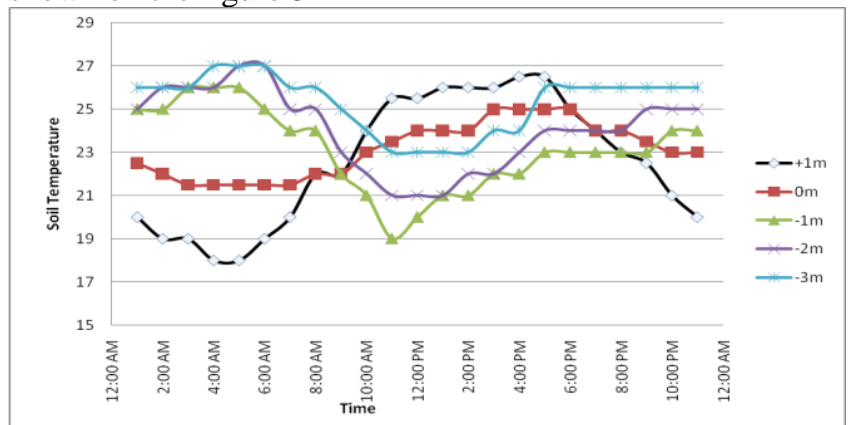

Figure 3: Soil temperature at various depths and ambient Temperature at KUET campus, Khulna at 23rd December 2008
From the figure it is seen that the temperature difference occurs maximum at the lowest level of the ground where we have determined to experiment. For summer season the data of 4th April 2008 has been shown on the figure 4

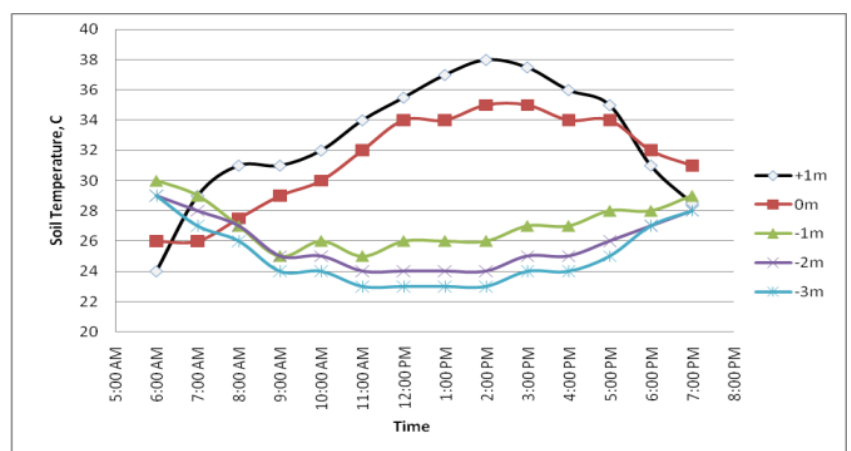

Figure 4: Ground temperature at various depths and ambient temperature at KUET campus, Khulna at 19th April 2008

From these data the deepest position at $3 \mathrm{~m}$ were selected for placing the GCHE as there is little fluctuation and wide difference of temperature was noticed

\section{FINAL INSTALLATION}

According to the design proposed the arrangement was installed at a depth of $3 \mathrm{~m}$ under the ground level. The design concept is illustrated through a CAD drawing in Figure 5 and actual picture if the setup before burying underground is shown in figure 6.

Data were taken during both summer and winter season. Temperature was measured at different distance of the tube to observe the change in air temperature with tube length. To do this several temperature sensors were placed at a certain distance on the tube. The sensors were calibrated properly before taking the data.

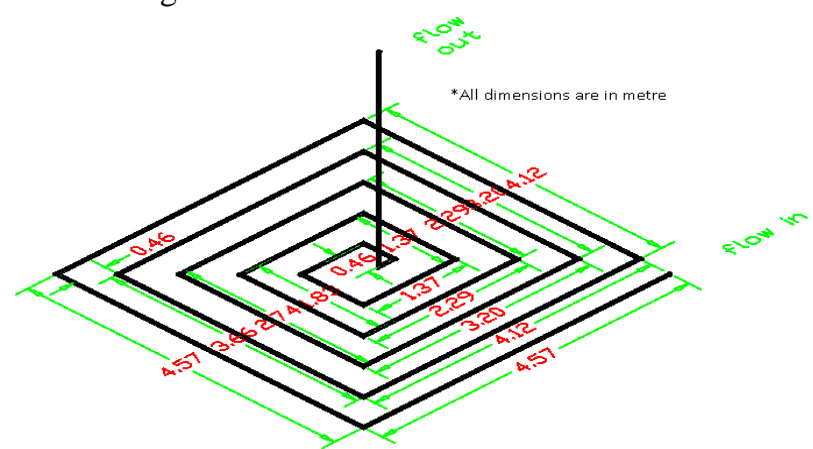

Figure 5: Three-Dimensional Concept of the GCHE

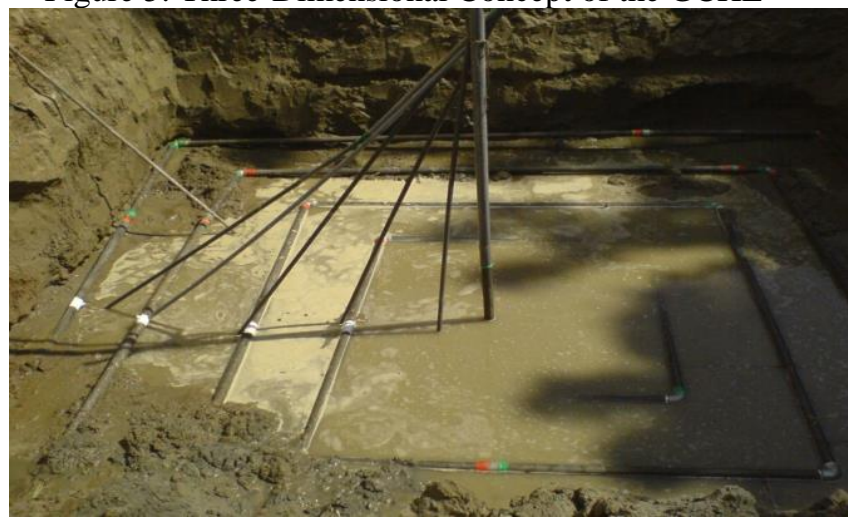

Figure 6: Final installation of GCHE before burying underground. 
Table 1: Air Temperature inside GCHE and Soil Temperature at 21.01.09

\begin{tabular}{|c|c|c|c|c|c|c|c|c|c|c|c|c|c|}
\hline $\begin{array}{c}\text { Time/ Temperature } \\
\left({ }^{\circ} \mathrm{C}\right)\end{array}$ & $\mathrm{T}_{+1 \mathrm{~m}}$ & $\mathrm{~T}_{0 \mathrm{~m}}$ & $\mathrm{~T}_{-1 \mathrm{~m}}$ & $\mathrm{~T}_{-2 \mathrm{~m}}$ & $\mathrm{~T}_{-3 \mathrm{~m}}$ & $\mathrm{~T}_{\text {Room }}$ & $\mathrm{T}_{0}$ & $\mathrm{~T}_{18.5}$ & $\mathrm{~T}_{34.3}$ & $\mathrm{~T}_{46.7}$ & $\mathrm{~T}_{55.2}$ & $\mathrm{~T}_{60.4}$ & $\mathrm{~T}_{82}$ \\
\hline 12:00pm & 23.5 & 24 & 24 & 25 & 26 & 23.5 & 23.5 & 23 & 24 & 24 & 25 & 25 & 25 \\
\hline 01:00am & 23.5 & 24 & 24 & 25 & 26 & 24 & 23.5 & 23 & 24 & 24 & 25 & 25 & 25 \\
\hline 02:00am & 23.5 & 25 & 24 & 25 & 26 & 24.5 & 23.5 & 23 & 23 & 24 & 25 & 25 & 25 \\
\hline 03:00am & 23.5 & 25 & 24 & 26 & 27 & 25 & 23.5 & 24 & 24 & 25 & 25 & 26 & 26 \\
\hline 06:00am & 22.5 & 24 & 24 & 25 & 26 & 25 & 22.5 & 22 & 23 & 24 & 25 & 25 & 25 \\
\hline 07:00am & 22.5 & 24 & 23 & 25 & 26 & 25 & 22.5 & 22 & 23 & 24 & 24 & 25 & 25 \\
\hline 08:00am & 23 & 24 & 23 & 25 & 25 & 25 & 23 & 23 & 23 & 24 & 24 & 25 & 25 \\
\hline
\end{tabular}

\section{RESUlTS AND ANALYSIS}

\section{A. Temperature Data during Winter}

The data acquired during a typical winter night from the GCHE in Khulna, Bangladesh at various tube length has been recorded in Table 1 and illustrated in Figure 7. It is evident that the underground temperature remains steady at relatively high temperature.

The temperature of the air at the inlet of the GCHE is initially low corresponding to the cold air temperature of the room. However, as it passes through the GCHE tube, it gets warmed up by exchanging heat from the ground.

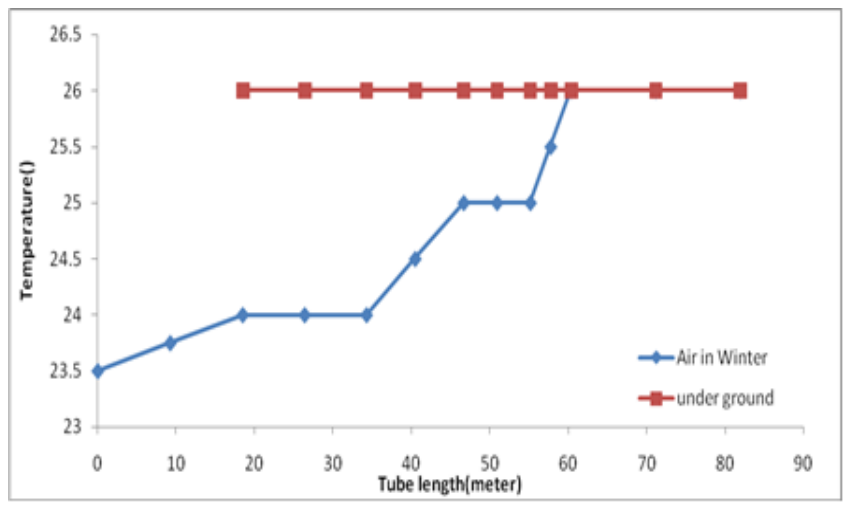

Figure 7: Air temperature inside GCHE and underground temperature under 3m depth at 3:00 AM (21 January 2009) at different length of GCHE

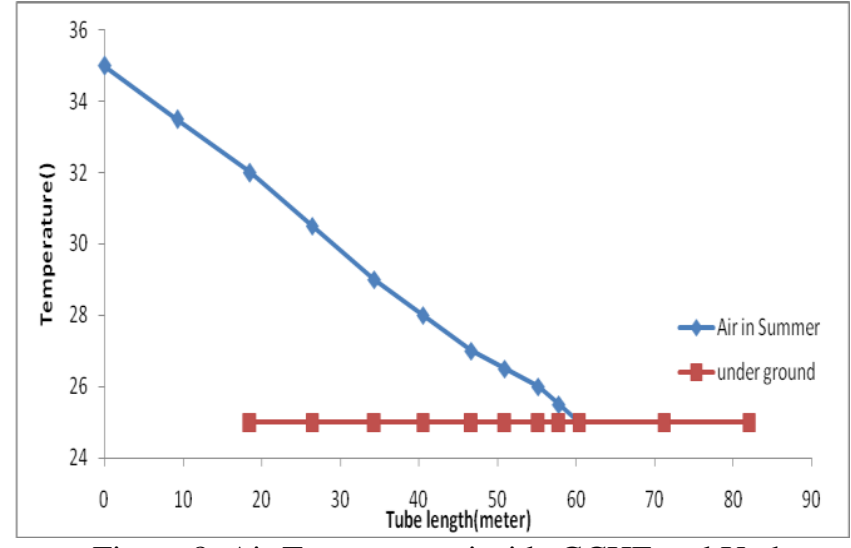

Figure 8: Air Temperature inside GCHE and Under Ground Temperature under 3m depth at 11:30 AM (26 March 2009) at different length of GCHE

\section{B. Temperature Data during Summer}

Likewise, the temperature data from the GCHE tube in a typical summer day in Khulna Bangladesh at various tube length has been recorded in Table 2 and graphically presented in figure 8. It can be observed that the temperature under the ground remain constant at low temperature and the inlet air. The temperature difference at $11.30 \mathrm{am}$ has been found $10^{\circ} \mathrm{C}$ which is quite significant for designing space cooling system temperature remains high. This temperature gradient helps to release heat from the circulating air in the ground and supply cool air in the test room.

Table 2: Air Temperature inside GCHE and Soil Temperature at 21.01.09

\begin{tabular}{|c|c|c|c|c|c|c|c|c|c|c|c|c|c|}
\hline Time/ Temperature $\left({ }^{\circ} \mathrm{C}\right)$ & $\mathrm{T}_{+1 \mathrm{~m}}$ & $\mathrm{~T}_{0 \mathrm{~m}}$ & $\mathrm{~T}_{-1 \mathrm{~m}}$ & $\mathrm{~T}_{-2 \mathrm{~m}}$ & $\mathrm{~T}_{-3 \mathrm{~m}}$ & $\mathrm{~T}_{\text {Room }}$ & $\mathrm{T}_{0}$ & $\mathrm{~T}_{18.5}$ & $\mathrm{~T}_{34.3}$ & $\mathrm{~T}_{46.7}$ & $\mathrm{~T}_{55.2}$ & $\mathrm{~T}_{60.4}$ & $\mathrm{~T}_{82}$ \\
\hline 10:30am & 23.5 & 24 & 24 & 25 & 26 & 29 & 34 & 26 & 32 & 28 & 26 & 25 & 25 \\
\hline 11:30am & 23.5 & 24 & 24 & 25 & 26 & 29 & 35 & 27 & 32 & 29 & 27 & 26 & 25 \\
\hline $12: 30 \mathrm{pm}$ & 23.5 & 25 & 24 & 25 & 26 & 29.5 & 36 & 28 & 33 & 30 & 28 & 26 & 24 \\
\hline $01: 30 \mathrm{pm}$ & 23.5 & 25 & 24 & 26 & 27 & 30 & 37 & 30 & 33 & 31 & 29 & 26 & 24 \\
\hline $02: 30 \mathrm{pm}$ & 23.5 & 25 & 24 & 26 & 27 & 31 & 36 & 32 & 32 & 30 & 29 & 25 & 24 \\
\hline
\end{tabular}




\section{Performance Analysis}

The design was made for a single room placed at the 1 st floor of ME building in which the cooling load was calculated as 4496.6 watt. To meet this cooling load requirement with the obtained temperature difference between the GCHE and room the mass flow rate requirement was found $0.319 \mathrm{~kg} / \mathrm{s}$. The required length and diameter of the tube was calculated by using various empirical heat transfer relations and the diameter was taken as $3.6 \mathrm{~cm}$ and the length $82 \mathrm{~m}$ including the inlet and outlet pipe. PVC pipe was used for the inlet and outlet pipe to reduce heat loss in the surrounding while passing through it. This air flow can be supplied by using a blower of $0.5 \mathrm{hp} \mathrm{(373} \mathrm{Watt).} \mathrm{Therefore,} \mathrm{the} \mathrm{Coefficient} \mathrm{of}$ Performance (COP) at cooling mode for the designed GCHE is

\section{$\mathrm{COP}=4496.6 / 373 \mathrm{So}, \mathrm{COP}=12.1$}

But there was some heat loss occurred at the outlet pipe and therefore the actual heat transferred was found as 2569.5 and hence the COP was found as 6.95 which is also a very good result because to meet the cooling load of the proposed room with conventional air conditioning system, the COP was calculated as 3.17 .

Again, the heating load for the same room during winter season was found as 2758 watt. To satisfy this heating load with the obtained temperature difference between room and GCHE the mass flow requirement was calculated as 0.304 $\mathrm{kg} / \mathrm{s}$. This air flow can be supplied by using a blower of $0.5 \mathrm{hp}$ (373 Watt). Therefore, the Coefficient of Performance (COP) at cooling mode is

\section{$\mathrm{COP}=2758 / 373$ So, $\mathrm{COP}=7.4$}

But due to heat loss occurred at the outlet pipe and the actual heat transferred was found as 765.3 and hence the COP was found as 2.07 which is also a good result.).

\section{CONCLUSIONS}

From this study, it concluded that this system is not suitable for sole heating or cooling of air due to its limitation of cooling or heating air up to a limited temperature. It can be used as a secondary system to reduce load from the primary and costly cooling system to save energy and cost. . However, the performance can further be augmented by applying proper insulation in the inlet and outlet flow from the delivery room till the ground. It has important potential for cooling as it is investment competitive with air-conditioning. During summer it can be used as bypass heat exchanger on exhaust air. From Bangladesh perspective, Ground Coupled Heat Exchanger can be used in places where lands are available. In rural places where Air conditioning facilities are not common and there are large fields available, GCHE can be employed there for conditioning room for both human and livestock buildings. It can also be used for grain storages in the locality.

\section{ACKNOWLEDGMENT}

The authors would like to thank Professor Dr Khandaker Aftab Hossain for his kind advice during the work and authority of Khulna University of Engineering and Technology for financial and administrative support to conduct the work.

\section{REFERENCES}

[1] Arora, C.P., 'Refrigeration and Air Conditioning', Tata McGraw-hill Publishing Company Limited, New Delhi, 2nd Edition.

[2] Ozisik, M.N., 'Heat Transfer: A Basic Approach', McGraw-hill Publishing Company Limited, New York, International Edition

[3] Girja Sharma, R.K Sahu, Ratan Jadhav, Air cooling and Heating System for Tiger in Zoo using Ground Ccoupled Heat Exchanger, February 2002.

[4] Girja Sharma, Ratan Jadhav, Soil Temperatures Regime at Ahmedabad, November 2002.

[5] G. Sharma, H. Prakash, R. Jadhav, Performance of Greenhouse Coupled to Earth-Tube-Heat-Exchanger in Closed-Loop Mode, March 2004.

[6] Girja Sharan, Ground Ccoupled Heat Exchangers for Environmental Control of Farm Buildings in Semi-Arid Northwest India, W.P. No.2008-01-02, January 2008

[7] Girja Sharan, Development and Some Applications of Ground Ccoupled Heat Exchanger in Gujarat, May 2005.

[8] Didier Thevenard, Bibliographic Search on the Potential of Earth Tubes, September 6, 2007.

[9] F.A. Ansari, A.S. Mokhtar, K.A. Abbas and N.M. Adam, A Simple Approach for Building Cooling Load Estimation, American Journal of Environmental Sciences 1 (3): 209-212, 2005.

[10] Girja Sharan, Ratan Jadhav, Performance of Single Pass Earth-Tube Heat Exchanger: An Experimental Study, July 2003.

[11] M.K.Ghosal, Sujata Nayak, G.N.Tiwari and N.Sahoo, Modeling and Experimental Study for Winter Performance of an Earth to Air Heat Exchanger: An Alternative Energy Source for Greenhouse, Agricultural Engineering International: the CIGR Ejournal. Manuscript EE 07 012. Vol. X. January 2008.

[12] ASHRAE Handbook, fundamentals 2001.

[13] F. C. McQuiston, J. D. Parker, J. D. Spitler, Heating, Ventilating, and Air Conditioning, Analysis and Design, 5th ed, John Wiley \& Sons, Inc, 2000

[14] C. O. Pedersen, D. E. Fisher, J. L. Richard, Development of a Heat Balance Procedure for Calculating Cooling Loads, ASHRAE Transactions, v 103, n 2, 1997

Mohammad Mahmudur Rahman is working as a Lecturer in the department of Industrial Engineering and Management in Khulna University of Engineering and Technology after graduating from the same university in 2009. His research interest is Experimental and Computational Fluid Mechanics, Heat and Mass transfer, Optimization technique.

Md Fahad Hossain currently working as Deputy Manager (Powerplant) in Akiz Cement factory. He has graduated from Department of Mechanical Engineering, Khulna University of Engineering and technology in 2009. His research interest is designing cooling systems, heat transfer and HVAC systems. 